\title{
Weight Loss Medications in Older Adults After Bariatric Surgery for Weight Regain or Inadequate Weight Loss: A Multicenter Study
}

\author{
Fatima Cody Stanford, MD, MPH, MPA, ${ }^{1-3,{ }^{\star}}$ Alexander T. Toth, BA, ${ }^{1, *}$ Alpana P. Shukla, MD, \\ Janey S. Pratt, MD, Hellas Cena, MD, Ginevra Biino, $\mathrm{PhD}^{7}$, and Louis J. Aronne, $\mathrm{MD}^{4}$
}

Weight loss medications are effective to confer additional weight loss after bariatric surgery in the general population, but they have not been evaluated in adults 60 years of age and older. We performed a retrospective study identifying 35 patients who were $\geq 60$ years old and had undergone Roux-en-Y gastric bypass (RYGB) or sleeve gastrectomy (SG) from 2000 to 2014, and were subsequently prescribed weight loss medications. Linear regression analyses were performed to determine beta coefficients of certain predictor variables being associated with weight loss. Patients lost weight on medications with an average body mass index (BMI) change of $-2.74 \mathrm{~kg} / \mathrm{m}^{2}$, standard deviation $=2.6 \mathrm{~kg} / \mathrm{m}^{2}$. RYGB patients lost a greater percentage of BMI on medication than SG (SG; $-1.38 \pm 1.49 \mathrm{~kg} / \mathrm{m}^{2}$ and RYGB; $-3.37 \pm 2.83 \mathrm{~kg} / \mathrm{m}^{2}, p=0.0372$ ). Patients with hypertension were less likely to lose weight on medications ( $\beta=16.76, p=0.004$, and 95\% confidence interval $=5.85-27.67)$. Weight loss medications are a useful treatment to confer additional weight loss in adults 60 years of age and older after RYGB and SG.

Keywords: bariatric surgery, weight loss medication, geriatric, older adults

\section{Introduction}

$\mathbf{O}$ BESITY IS THE MOST COMMON CHRONIC DISEASE in the United States and is linked to comorbidities, including type 2 diabetes, hypertension, obstructive sleep apnea (OSA), non-alcoholic fatty liver disease (NAFLD), and cancer. ${ }^{1,2}$ Over one third of men and women older than 60 years of age, have obesity in the United States ${ }^{3}$ and as the population ages, the number of people older than 60 years of age with obesity continues to rise. In addition to comorbidities, obesity in older persons is associated with increased dependency on others to carry out activities of daily living. ${ }^{4}$ Older adults with obesity are twice as likely to be admitted to nursing homes, enter nursing homes earlier, and require additional equipment, supplies, and staff. ${ }^{5}$ Bariatric surgery is the most effective treatment for moderate and severe obesity in older patients. ${ }^{6-9}$ Weight loss surgery in adults older than 60 years of age is effective, safe, and in addition to weight loss, leads to the resolution or improvement of comorbidities, particularly hypertension and diabetes. ${ }^{10-14}$ While there are distinctive hormonal and metabolic changes that occur with surgery, much of the comorbidity improvement seems to be conferred by dramatic weight loss that occurs with surgical treatment compared to other weight loss therapies. ${ }^{15,16} \mathrm{Un}$ fortunately, there is a variable response to bariatric surgery and some patients have suboptimal weight loss or experience weight regain after bariatric surgery. ${ }^{17,18}$ These patients are in need of further treatment options to confer additional weight loss or to reachieve weight loss following bariatric surgery. Pharmacotherapy is a promising treatment method that has been shown to be effective in helping achieve additional weight loss in patients from a wide range of ages following bariatric surgery. ${ }^{19}$ In this study, we sought to evaluate the effectiveness of weight loss medications in patients older than 60 years of age, who had Roux-en-Y gastric bypass (RYGB) surgery or sleeve gastrectomy (SG), and

\footnotetext{
${ }^{1}$ Neuroendocrine Unit, Department of Medicine, Massachusetts General Hospital, Boston, Massachusetts.

${ }^{2}$ Endocrinology, Department of Pediatrics, Massachusetts General Hospital, Boston, Massachusetts.

${ }^{3}$ Harvard Medical School, Boston, Massachusetts.

${ }^{4}$ Comprehensive Weight Control Center, Division of Endocrinology, Diabetes, and Metabolism, Department of Medicine, Weill Cornell Medical College, New York, New York.

${ }^{5}$ Department of Surgery, Lucille Packard Children's Hospital and Stanford University School of Medicine, Palo Alto, California.

${ }^{6}$ Unit of Human Nutrition and Dietetics, Department of Public Health, Experimental and Forensic Medicine, University of Pavia, Pavia, Italy.

${ }^{7}$ Institute of Molecular Genetics, National Research Council of Italy, Pavia, Italy,

*Both these authors contributed equally to this work.
} 
were subsequently prescribed weight loss medications. We hypothesized that the use of weight loss medications would yield further weight loss following RYGB and SG. The primary consideration in this article is whether medications are beneficial in older patients ( $\geq 60$ years of age) as an adjunct to weight loss surgery for inadequate weight loss or weight regain, as this population tends to have more contraindications to the chronic use of weight loss medications and there is a concern with polypharmacy in this population.

\section{Methods}

\section{Sample and data collection}

The patients in our study sample came from two major academic medical centers where they underwent RYGB or SG procedures between November 2000 and June 2014. From our sample, all patients who were 60 years of age or older and were subsequently placed on weight loss medications after surgery were considered for inclusion. All patients had at least 12 months of documented postoperative followup. Patients were excluded if they did not have sufficient follow-up considered to be at least one annual visit, had additional surgery for complications within 6 months of their initial surgery, or if they required a revision surgery. Two research groups obtained the clinical data from the medical record and the study was approved by the Institutional Review Boards at both academic centers.

\section{Demographic and clinical factors}

We obtained the following data from the medical records of eligible patients: (1) type of surgery (RYGB or SG); (2) date of operation; (3) date of birth; (4) gender; (5) race/ethnicity (Caucasian, Hispanic, Black, Asian, or other); (6) preoperative obesity-related comorbidities (hypertension, type 2 diabetes, OSA, dyslipidemia, and NAFLD); (7) preoperative use of weight loss medications; (8) body mass index (BMI; based on initial height and weight at the following time points: presurgery, at plateau postsurgery, at the start of weight loss medication, at plateau after weight loss medication, and current); (9) time to achieve plateau weight postsurgery; (10) postoperative resolution of obesity comorbidities; (11) continued use of weight loss medication(s); (12) psychiatric comorbidity (anxiety, depression, and bipolar disorder); (13) use of psychotropic medications presurgery; and (14) use of psychotropic medications postsurgery.

\section{Weight loss medications}

We collected information on 15 medications that are prescribed by obesity medicine physicians at the two academic centers. We reviewed the entire electronic medical record to determine if there was history of the medication being prescribed and filled at the pharmacy by the patient. The medications included were as follows: (1) phentermine, (2) topiramate, (3) zonisamide, (4) metformin, (5) bupropion, (6) orlistat, (7) sibutramine, (8) liraglutide, (9) exenatide, (10) pramlintide, (11) naltrexone, (12) lorcaserin, (13) phentermine/topiramate, (14) canagliflozin, and (15) bupropion/ naltrexone.

\section{Primary endpoints}

The primary endpoint was relative change in weight. Additional secondary efficacy endpoints were changes in BMI and the resolution of obesity related comorbidities, which, listed with the criteria that we used to determine resolution, were as follows: (1) hypertension-no longer requiring medication to maintain a normal blood pressure of $<120 / 80$; (2) type 2 diabetes-no longer requiring medications to maintain a hemoglobin A1c of $<6.5$; (3) OSA - no longer requiring continuous positive airway pressure as assessed by overnight polysomnography; (4) dyslipidemia-normalization of lipid values without lipidlowering therapy; and (5) NAFLD-normalization of liver function tests. (6) Mental illness-no longer requiring medication or undergoing therapy to treat the condition.

\section{Statistical analysis}

The data we collected were used to create variables for analysis. Patient weight histories, including nadir weight after surgery before medical treatment denoted as "nadirpre," weight at initiation of weight loss medication treatment, and weight at nadir after weight loss medication treatment denoted as "nadir-post," were summarized with descriptive statistics overall and broken out by surgery type (RYGB or SG). Baseline demographic characteristics and preoperative baseline characteristics were also included. The treatment period of medications was determined by the time between the date weight loss medications were initiated to the date when nadir-post weight was achieved. Patients were split into two groups based on when weight loss medication treatment was started postsurgery. The distinction between the two groups was whether medication was started at plateau weight or after weight regain had already occurred. Patients were at plateau weight if their weight was no more than $3 \%$ greater than their postsurgery nadir-pre weight. Patients who were not within $3 \%$ of their postsurgery nadir-pre weight were considered to have started medication after weight regain. The patients in the study did not have to be within $3 \%$ of their nadir-pre weight for a certain period of time postoperative because the time to achieve nadir-pre varies among patients as well as by type of surgery. Patients did, however, need to demonstrate at least 3 months of weight stability.

Linear regression analyses were performed to build a model with medications used over the treatment period as our candidate predictor variables for weight loss. We adjusted for the type of surgery performed and patient BMI at the start of weight loss medication treatment by including them as covariates in our model. These variables were controlled for because they have influenced weight loss using weight loss medication in other studies. ${ }^{19}$ We then performed linear regression analyses with candidate predictor variables based on our demographic and baseline characteristics. Beta coefficients $(\beta)$ and corresponding $p$ values were estimated. Negative beta coefficients were indicative of increased weight loss and positive beta coefficients were indicative of decreased weight loss. All analyses were performed in Stata Version 11.

\section{Results \\ Participants}

Baseline characteristics of study patients are noted in Table 1 . Of the 5110 patient records that were reviewed, 35 
Table 1. Demographic Data and Baseline Characteristics for Patients $>60$

\begin{tabular}{|c|c|c|c|}
\hline \multirow[b]{3}{*}{ Variable } & \multirow{3}{*}{$\frac{\text { All patients }}{\mathrm{n}=35}$} & \multicolumn{2}{|c|}{ Surgery type } \\
\hline & & \multirow{2}{*}{$\frac{\text { Sleeve gastrectomy }}{\mathrm{n}=11(31.4 \%)}$} & \multirow{2}{*}{$\frac{R Y G B}{\mathrm{n}=24(68.6 \%}$} \\
\hline & & & \\
\hline \multicolumn{4}{|l|}{ Gender, $n(\%)$} \\
\hline Female & $26(74.3)$ & $8(72.7)$ & $18(75)$ \\
\hline Male & $9(25.7)$ & $3(27.3)$ & $6(25)$ \\
\hline \multicolumn{4}{|l|}{ Age at surgery (years), $n(\%)$} \\
\hline $60-64$ & $19(54.3)$ & $5(45.5)$ & $14(58.3)$ \\
\hline $65-69$ & $14(40)$ & $5(45.5)$ & $9(37.5)$ \\
\hline $70+$ & $2(5.7)$ & $1(9.0)$ & $17(74)$ \\
\hline \multicolumn{4}{|l|}{ Race/ethnicity, $n(\%)$} \\
\hline White & $29(82.8)$ & $10(90.9)$ & $19(82.8)$ \\
\hline Hispanic & $1(2.9)$ & 0 & $1(2.9)$ \\
\hline African American & $4(11.4)$ & $1(9.1)$ & $1(4.2)$ \\
\hline Asian & 0 & 0 & 0 \\
\hline Other/declined to state & $1(2.9)$ & 0 & $1(2.9)$ \\
\hline \multicolumn{4}{|c|}{ Preoperative characteristics, mean (SD) } \\
\hline Weight (lbs) & $273(43)$ & $274(45)$ & $273(43)$ \\
\hline BMI (lbs/inches²) & $44.3(6.2)$ & $43.2(4.3)$ & $44.8(6.9)$ \\
\hline \multicolumn{4}{|l|}{ Obesity class, $n(\%)$} \\
\hline Class I (BMI 30-34.9) & 0 & 0 & 0 \\
\hline Class II (BMI 35-39.9) & $10(29)$ & $3(27)$ & $7(29)$ \\
\hline Class III $(\mathrm{BMI} \geq 40)$ & $25(72)$ & $8(73)$ & 17 (71) \\
\hline \multicolumn{4}{|c|}{ Comorbid conditions (individual), $n(\%)$} \\
\hline Hypertension & $27(77)$ & $9(33)$ & $18(67)$ \\
\hline Type II diabetes & $18(51)$ & $4(22)$ & $14(78)$ \\
\hline OSA & $12(34)$ & $5(42)$ & $7(58)$ \\
\hline Dyslipidemia & $28(80)$ & $8(29)$ & $20(71)$ \\
\hline NAFLD & $25(71)$ & $7(28)$ & $18(72)$ \\
\hline Mental illness ${ }^{\mathrm{a}}$ & $18(51)$ & $6(33)$ & $12(67)$ \\
\hline \multicolumn{4}{|c|}{ No. of comorbid conditions, $n(\%)$} \\
\hline None & $1(3)$ & $1(100)$ & $0(0)$ \\
\hline 1 & $2(6)$ & $1(50)$ & $1(50)$ \\
\hline 2 & $6(17)$ & $1(17)$ & $5(83)$ \\
\hline 3 & $10(28)$ & $3(30)$ & $7(70)$ \\
\hline 4 & $14(40)$ & $4(29)$ & $10(71)$ \\
\hline 5 & $2(6)$ & $1(50)$ & $1(50)$ \\
\hline
\end{tabular}

${ }^{\mathrm{a}}$ Based on variable Psychiatric Comorbidity-Yes/No.

BMI, body mass index; NAFLD, non-alcoholic fatty liver disease; OSA, obstructive sleep apnea; RYGB, Roux-en-Y gastric bypass; SD, standard deviation.

$(0.6 \%)$ met criteria for inclusion. Almost three quarters of patients were female $(n=26 ; 74.3 \%)$ and a little over one quarter of patients were male $(n=9 ; 25.7 \%)$. All patients were 60 years of age or older at the start of medication therapy with $19(54.3 \%)$ patients between 60 and 64 years of age, $14(40 \%)$ patients between 65 and 69 years of age, and $2(5.7 \%)$ patients being 70 years of age or older. Patients were predominantly white, $19(82.8 \%)$ of the patients identified as Caucasian, 1 (2.9\%) identified as Hispanic, 4 (11.4\%) identified as African American, and 1 (2.9\%) declined to answer or identified as a different race. At the time of surgery, RYGB patients had a slightly higher mean BMI $\left(44.8 \mathrm{~kg} / \mathrm{m}^{2}\right.$; standard deviation $[\mathrm{SD}]=6.9)$ versus $\left(43.2 \mathrm{~kg} / \mathrm{m}^{2} ; \mathrm{SD}=4.3\right)$. Before surgery, the RYGB group also had higher percentages of obesity-related comorbidities and took longer to reach their weight plateau after surgery. At the start of medication, as denoted in Table 2, the mean weight and BMI of RYGB $\left(\mathrm{BMI}=34.7 \mathrm{~kg} / \mathrm{m}^{2} ; \mathrm{SD}=5.8\right)$ and $\mathrm{SG}\left(\mathrm{BMI}=36.6 \mathrm{~kg} / \mathrm{m}^{2}\right.$; $\mathrm{SD}=3.6)$ were similar, but RYGB patients had a longer time elapse between surgery (38.5 months; $\mathrm{SD}=28.6)$ and the start of medication compared with patients who had SG (26.2 months; $\mathrm{SD}=13.2$ ). At the nadir-post weight achieved after weight loss medication, the mean BMI for patients in the RYGB group was also similar to that of the $S G$ group, RYGB $\left(B M I=31.3 \mathrm{~kg} / \mathrm{m}^{2}\right.$; $\mathrm{SD}=5.7)$ and $\mathrm{SG}\left(\mathrm{BMI}=35.2 \mathrm{~kg} / \mathrm{m}^{2} ; \mathrm{SD}=3.8\right)$.

\section{Weight loss medications and response}

Both the RYGB and SG groups were often trialed on several medications over the course of treatment. The average number of medications was 2.2 (SD=1.3) (Table 3). Patients were more likely to be prescribed medications after weight regain $(71.4 \% ; n=25)$ had occurred than at plateau $(28.6 \%$; $n=10$ ) (Table 4). Overall, the patients in this cohort lost weight on medication, with an average BMI change of $-2.74 \mathrm{~kg} / \mathrm{m}^{2}$, $\mathrm{SD}=2.6 \mathrm{~kg} / \mathrm{m}^{2}$. Patients prescribed medications at their plateau weight saw a slightly greater $\left(-3.53 \pm 3.39 \mathrm{~kg} / \mathrm{m}^{2}\right)$ decrease in BMI compared to patients who were prescribed medication 
Table 2. Postoperative Patient Characteristics and Weight History After Surgery, Before Medications, and After Treatment

\begin{tabular}{|c|c|c|c|}
\hline & All patients & Sleeve gastrectomy & $R Y G B$ \\
\hline Comorbid conditions (individual), $n(\%)$ & 35 & $11(31.4)$ & $24(68.6)$ \\
\hline $\begin{array}{l}\text { Hypertension, } n(\%) \\
\text { Preoperative patients }(n=27) \text { who achieved resolution }(\%)\end{array}$ & $9(33.3)$ & $2 / 9(22.2)$ & $7 / 18(39.8)$ \\
\hline $\begin{array}{l}\text { Type II diabetes, } n(\%) \\
\text { Preoperative patients }(n=18) \text { who achieved resolution }(\%)\end{array}$ & $7(39.8)$ & $2 / 4(50)$ & $5 / 14(35.7)$ \\
\hline $\begin{array}{l}\text { OSA, } n(\%) \\
\quad \text { Preoperative patients }(n=12) \text { who achieved resolution }(\%)\end{array}$ & $7(53.3)$ & $0 / 5(0)$ & $7 / 7(100)$ \\
\hline $\begin{array}{l}\text { Dyslipidemia, } n(\%) \\
\text { Preoperative patients }(n=28) \text { who achieved resolution }(\%)\end{array}$ & $15(53.6)$ & $2 / 8(25)$ & $13 / 20(65)$ \\
\hline $\begin{array}{l}\text { NAFLD, } n(\%) \\
\quad \text { Preoperative patients }(n=25) \text { who achieved resolution }(\%)\end{array}$ & $18(72)$ & $4 / 7(57.1)$ & $14 / 18(77.8)$ \\
\hline $\begin{array}{l}\text { Mental illness, }{ }^{\text {a }} n(\%) \\
\text { Preoperative patients }(n=17) \text { who achieved resolution }(\%) \\
\text { Postoperative nadir weight before medication, } n(\%) \\
\text { BMI (lbs/inches }{ }^{2} \text {, mean (SD) } \\
\text { Time to achieve nadir (months), mean (SD) } \\
\text { Average weight loss at nadir weight (lbs), mean (SD) }\end{array}$ & $\begin{array}{l}15(88.2) \\
35 \\
33.0(5.4) \\
12.6(6.8) \\
70.0(28.7)\end{array}$ & $\begin{aligned} 5 / 5 & (100) \\
11 & (31.4) \\
35.1 & (3.6) \\
10.4 & (7.5) \\
52.4 & (28.2)\end{aligned}$ & $\begin{array}{r}10 / 12(83.3) \\
24(68.6) \\
32.1(5.9) \\
13.6(6.3) \\
78.0(25.5)\end{array}$ \\
\hline $\begin{array}{l}\text { At start of medication, mean (SD) } \\
\text { Weight (lbs) } \\
\left.\text { BMI (lbs/inches }{ }^{2}\right)\end{array}$ & $\begin{array}{c}217.9(35.6) \\
33.3(5.3)\end{array}$ & $\begin{array}{l}231.1(30.1) \\
36.6(3.6)\end{array}$ & $\begin{array}{r}211.9(36.9) \\
34.7(5.8)\end{array}$ \\
\hline $\begin{array}{l}\text { Time elapsed between surgery and start of medication (months } \\
\text { Mean (SD) } \\
\text { Minimum } \\
\text { Maximum }\end{array}$ & $\begin{array}{l}34.6(25.3) \\
12.3 \\
133.4\end{array}$ & $\begin{array}{l}26.2(13.2) \\
12.3 \\
51.3\end{array}$ & $\begin{array}{l}38.5(28.6) \\
13.1 \\
133.4\end{array}$ \\
\hline $\begin{array}{l}\text { Postmedication treatment-at nadir weight, mean (SD) } \\
\text { Weight (lbs) } \\
\text { BMI (lbs/inches }{ }^{2} \text { ) } \\
\text { Weight gain between nadir and medication initiation (BMI) } \\
\text { Weight loss with medications at new nadir (BMI) }\end{array}$ & $\begin{aligned} & 201.3(38.4) \\
& 32.6(5.5) \\
& 2.33(2.86) \\
& 2.80(2.59)\end{aligned}$ & $\begin{aligned} 222.2 & (29.5) \\
35.2 & (3.8) \\
1.55 & (3.80) \\
1.53 & (1.34)\end{aligned}$ & $\begin{array}{r}191.8(38.6) \\
31.3(5.7) \\
2.69(2.33) \\
3.37(2.83)\end{array}$ \\
\hline
\end{tabular}

\footnotetext{
${ }^{\mathrm{a}}$ Missing data for one patient.

${ }^{\mathrm{b}} n=35$.
}

after weight regain $\left(-2.43 \pm 2.27 \mathrm{~kg} / \mathrm{m}^{2}\right)(p=0.2730)$, but this difference was not found to be significant (Table 4$)$.

The most frequently prescribed medications were topiramate, phentermine, metformin, bupropion, zonisamide, lorcaserin, and liraglutide (Table 5). In our model, which was adjusted for type of surgery and BMI at the start of medication, beta coefficients are shown in Table 5 for each medication as a predictor of weight loss. A significant beta coefficient was observed for liraglutide, $(\beta=-16.07, p=$ 0.009 , confidence interval $[\mathrm{CI}]=-25.17$ to 3.57 ).

\section{Predictors of weight loss medication response}

RYGB patients had greater BMI decreases on medication than SG that were statistically significant, (SG; $-1.38 \pm$ $1.49 \mathrm{~kg} / \mathrm{m}^{2}, \mathrm{RYGB} ;-3.37 \pm 2.83 \mathrm{~kg} / \mathrm{m}^{2}, p=0.0372$ ) (Table 4).

Table 3. Weight Loss Medications Use

\begin{tabular}{|c|c|c|c|}
\hline & \multirow[b]{2}{*}{ All patients } & \multicolumn{2}{|c|}{ Surgery type } \\
\hline & & Sleeve gastrectomy & $R Y G B$ \\
\hline & $\mathrm{n}=35$ & $\mathrm{n}=11(31.4 \%)$ & $\mathrm{n}=24(68.6 \%)$ \\
\hline \multicolumn{4}{|c|}{ No. of medications trialed over treatment course, $n(\%)$} \\
\hline One & $15(43)$ & $3(20)$ & $12(80)$ \\
\hline Two & $8(23)$ & $2(25)$ & $6(65)$ \\
\hline Three & $6(17)$ & $4(67)$ & $2(33)$ \\
\hline Four & $4(11)$ & $2(50)$ & $2(50)$ \\
\hline Five & $1(3)$ & $0(0)$ & $1(100)$ \\
\hline Six & $1(3)$ & $0(0)$ & $1(100)$ \\
\hline $\begin{array}{l}\text { No. of medications prescribed over } \\
\text { treatment period, mean (SD) }\end{array}$ & $2.2(1.3)$ & $2.4(1.1)$ & $2.0(1.4)$ \\
\hline
\end{tabular}


Table 4. Mean Body Mass Index Change After Treatment by Subgroup

\begin{tabular}{|c|c|c|c|c|}
\hline \multirow[b]{2}{*}{ Subgroup } & \multicolumn{2}{|c|}{ BMI change } & \multirow[b]{2}{*}{$\mathrm{p}$} & \multirow[b]{2}{*}{$95 \% C I$} \\
\hline & BMI, mean (SD) & $\%, \operatorname{Mean}(S D)^{\mathrm{a}}$ & & \\
\hline All patients $(n=35)$ & $-2.74(2.6)$ & $-8(7)$ & & \\
\hline $\begin{array}{l}\text { Patients prescribed medication } \\
\text { at weight plateau }(n=10,28.6 \%)^{\text {b }}\end{array}$ & $-3.53(3.39)$ & $-9(8)$ & $0.2730^{\mathrm{c}}$ & -3.6 to -1.8 \\
\hline $\begin{array}{l}\text { Patients prescribed medication } \\
\text { at weight regain }(n=25,71.4 \%)^{\mathrm{b}}\end{array}$ & $-2.43(2.27)$ & $-7(7)$ & & \\
\hline $\begin{array}{l}\text { Surgery type } \\
\text { Sleeve gastrectomy }(n=11) \\
\text { RYGB }(n=24)\end{array}$ & $\begin{array}{l}-1.38(1.49)^{\mathrm{d}} \\
-3.37(2.83)^{\mathrm{d}}\end{array}$ & $\begin{array}{l}-3.7(4) \\
-9.5(7)\end{array}$ & $0.0372^{c}$ & $\begin{array}{l}-2.39 \text { to }-0.38 \\
-4.56 \text { to }-2.17\end{array}$ \\
\hline
\end{tabular}

We also evaluated other specific predictors of response to weight loss medications as summarized in Table 6. No statistically significant difference in beta values was found for gender, age range, weight when medications were prescribed, race, BMI at baseline preoperatively, BMI at start of medications, or time to achieve nadir-pre weight after surgery before medications were prescribed. The number of comorbidities at the time of surgery did not yield statistically significant changes to beta values; however, hypertension at the time of surgery did have a significantly large beta value $\left(\beta=16.76, p=0.004, \mathrm{CI}=5.85-27.67, R^{2}=0.3485\right)$.

\section{Discussion}

The use of weight loss medications has been shown to help patients across a broad range of ages lose additional weight after bariatric procedures, but the use of weight loss medications in patients 60 years of age and older has not been thoroughly studied. ${ }^{19-23}$ Our study demonstrates the utility of weight loss medications for additional weight loss in patients 60 years of age or older, following RYGB and SG. The mean BMI change achieved with medications was $-2.74 \pm 2.6 \mathrm{~kg} /$ $\mathrm{m}^{2}$. Figure 1 depicts a representative example of a 72 -yearold patient included in our study, who achieved weight loss with the use of pharmacotherapy after RYGB surgery. We did not find a statistically significant difference in BMI de- crease when medications were prescribed at weight plateau $\left(-3.53 \pm 3.39 \mathrm{~kg} / \mathrm{m}^{2}\right)$ versus at weight regain $(-2.43 \pm$ $\left.2.27 \mathrm{~kg} / \mathrm{m}^{2} ; p=0.2730\right)$, which is in line with previous findings on weight loss medication use postsurgery. ${ }^{19-23}$ While further prospective studies are needed, response to pharmacotherapy after weight loss surgery may be governed by a threshold paradigm that has been observed in other weight loss therapies where higher starting BMIs result in anabolic responses due to adiposity-related signals that occur at a higher threshold. ${ }^{24}$ Thus, initiating pharmacotherapy at the initial nadir-pre weight instead of following weight regain after surgery may be the ideal time to commence therapy to achieve maximal overall weight loss; however, our research did not prove this as the differences in weight loss observed were not statistically significant.

Liraglutide was the only medication to show a significant negative beta coefficient in our linear regression analysis using medication as a predictor of weight loss $(\beta=-16.07$, $p=0.009$, and $\mathrm{CI}=-27.76$ to -4.38$)$. It is important to note that after Bonferroni correction, the $p$-value adopted for this analysis is 0.005 and therefore, Liraglutide seems to be approaching a significant beta coefficient, but still remains the only medication in this analysis that comes close to a $p$-value of 0.005 . The negative beta coefficient may portend a higher likelihood of weight loss when using Liraglutide in this older cohort. Liraglutide is an acylated glucagon-like peptide-1

Table 5. Linear Regression Analysis with Medication as Predictor

\begin{tabular}{|c|c|c|c|c|}
\hline \multirow[b]{2}{*}{ Medication } & \multirow[b]{2}{*}{ No. of patients (\%) } & \multicolumn{3}{|c|}{ Treatment period weight loss } \\
\hline & & $\beta$ & $\mathrm{p}$ & $95 \% C I$ \\
\hline Topiramate & $20(57.1)$ & -6.56 & 0.230 & -17.47 to 4.35 \\
\hline Phentermine & $10(28.6)$ & 3.35 & 0.558 & -8.19 to 14.9 \\
\hline Metformin & $14(40.0)$ & -6.72 & 0.193 & -17.02 to 3.57 \\
\hline Bupropion & $4(11.4)$ & -7.54 & 0.343 & -23.49 to 8.42 \\
\hline Zonisamide & $8(22.9)$ & 0.59 & 0.924 & -11.93 to 13.12 \\
\hline Lorcaserin & $5(14.3)$ & -10.80 & 0.136 & -25.17 to 3.57 \\
\hline Liraglutide & $7(20.0)$ & -16.07 & 0.009 & -27.76 to -4.38 \\
\hline Qsymia & $1(2.9)$ & -7.96 & 0.614 & -39.84 to 23.91 \\
\hline Naltrexone & $3(8.6)$ & -7.67 & 0.458 & -28.49 to 13.15 \\
\hline Bupropion/naltrexone & $3(8.6)$ & 3.05 & 0.745 & -15.91 to 22 \\
\hline
\end{tabular}


Table 6. Linear Regression by Predictor Variable

\begin{tabular}{|c|c|c|c|c|}
\hline \multirow[b]{2}{*}{ Predictor } & \multicolumn{4}{|c|}{ Treatment period weight loss } \\
\hline & $\beta$ & $\mathrm{p}$ & $95 \% C I$ & $\mathrm{R}^{2}$ \\
\hline \multicolumn{5}{|l|}{ Surgery type } \\
\hline Gastrectomy (reference) & Ref. & & & \\
\hline RYGB & -11.29 & 0.043 & -22.21 to -0.37 & 0.0915 \\
\hline $\mathrm{RYGB}^{\mathrm{a}}$ & -12.38 & 0.029 & -23.42 to -1.34 & 0.1012 \\
\hline RYGB $^{\mathrm{b}}$ & -11.64 & 0.046 & -23.03 to -0.24 & 0.0652 \\
\hline \multicolumn{5}{|l|}{ Gender } \\
\hline Male (reference) & Ref. & & & \\
\hline Female & -5.69 & 0.349 & -17.88 to 6.5 & 0.0266 \\
\hline Female $^{\mathrm{c}}$ & -5.41 & 0.351 & -17.04 to 6.23 & 0.0886 \\
\hline Age (every 1 year increase) & 0.34 & 0.661 & -1.21 to 1.88 & 0.0059 \\
\hline \multicolumn{5}{|l|}{ Weight when medications prescribed } \\
\hline At plateau (reference) & Ref. & & & \\
\hline At regain & 4.30 & 0.465 & -7.55 to 16.16 & 0.0163 \\
\hline At regain ${ }^{\mathrm{a}, \mathrm{d}}$ & 2.98 & 0.607 & -8.73 to 14.68 & 0.0702 \\
\hline \multicolumn{5}{|l|}{ Race/ethnicity } \\
\hline Caucasian (reference) & Ref. & & & \\
\hline All other & -3.27 & 0.644 & -17.55 to 11.01 & 0.0065 \\
\hline \multicolumn{5}{|l|}{ BMI class - at baseline preoperatively } \\
\hline For 1 unit increase & -0.65 & 0.133 & -1.51 to 0.21 & 0.0671 \\
\hline Class II (reference) & Ref. & & & \\
\hline Class III & -6.80 & 0.246 & -18.5 to 4.91 & 0.0406 \\
\hline \multicolumn{5}{|l|}{ Comorbities-No. present at preoperative ${ }^{\mathrm{d}}$} \\
\hline 0 (Reference) & Ref. & & & \\
\hline 1 & 3.60 & 0.841 & -32.85 to 40.05 & 0.3183 \\
\hline 2 & -6.16 & 0.707 & -39.37 to 27.05 & \\
\hline 3 & -6.13 & 0.697 & -38.08 to 25.82 & \\
\hline 4 & 7.81 & 0.619 & -24.01 to 39.63 & \\
\hline 5 & 2.42 & 0.894 & -34.55 to 39.39 & \\
\hline \multicolumn{5}{|l|}{ Type of comorbidity ${ }^{\mathrm{d}}$} \\
\hline Hypertension & 16.76 & 0.004 & 5.85 to 27.67 & 0.3485 \\
\hline Diabetes & 0.50 & 0.923 & -10.08 to 11.09 & 0.1839 \\
\hline OSA & -0.03 & 0.996 & -11.15 to 11.1 & 0.1422 \\
\hline Dyslipidemia & 5.22 & 0.419 & -7.79 to 18.23 & 0.1604 \\
\hline NAFLD & -0.76 & 0.897 & -12.61 to 11.08 & 0.1427 \\
\hline Mental illness & 1.42 & 0.782 & -8.94 to 11.78 & 0.1444 \\
\hline \multicolumn{5}{|c|}{ Time to achieve nadir weight postoperative before medications ${ }^{\mathrm{d}, \mathrm{e}}$} \\
\hline$\leq 12$ Months (reference) & Ref. & & & \\
\hline 13-36 Months & -1.48 & 0.781 & -12.22 to 9.27 & 0.1444 \\
\hline$>36$ Months & NA & & & \\
\hline BMI at start of medications (every 1 unit increase) & -0.37 & 0.466 & -1.4 to 0.66 & 0.0162 \\
\hline
\end{tabular}

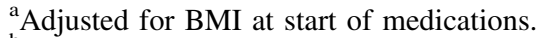

${ }^{\mathrm{b}}$ Adjusted time elapse between surgery date and start of medications.

${ }^{c}$ Adjusted for type of surgery by including as covariate.

${ }^{\mathrm{d}}$ Adjusted for type of surgery and gender.

$\mathrm{e}_{n=35}$.

NA, not applicable.

analogue that has a different mechanism of action than many of the other weight loss medications trialed. ${ }^{25}$ Furthermore, in a previous study of multiple weight loss medications used in a broader age range of patients, topiramate appeared to confer the highest weight loss potential. ${ }^{19}$ Therefore, the question of whether Liraglutide is particularly efficacious in older populations of patients following bariatric surgery needs further study.

We did not find the number of comorbidities present before weight loss surgery to influence weight loss postsurgery. However, the presence of hypertension before weight loss surgery resulted in a significant positive beta coefficient $(\beta=16.76$, $p=0.004$, and $\mathrm{CI}=5.85-27.67$ ), which suggests that the presence of hypertension before surgery may decrease the likelihood of weight loss with medication therapy. Patients with hypertension do present a clinical challenge as many weight loss medications that might be considered might worsen hypertension or be a relative or absolute contraindication to their use. This is particularly germane to the use of stimulant medications such as phentermine. Research is limited, but this result is paradoxical to findings in a study by Shantavasinkul where hypertension was correlated with sustained weight 


\section{2 year old woman s/p RYGB}

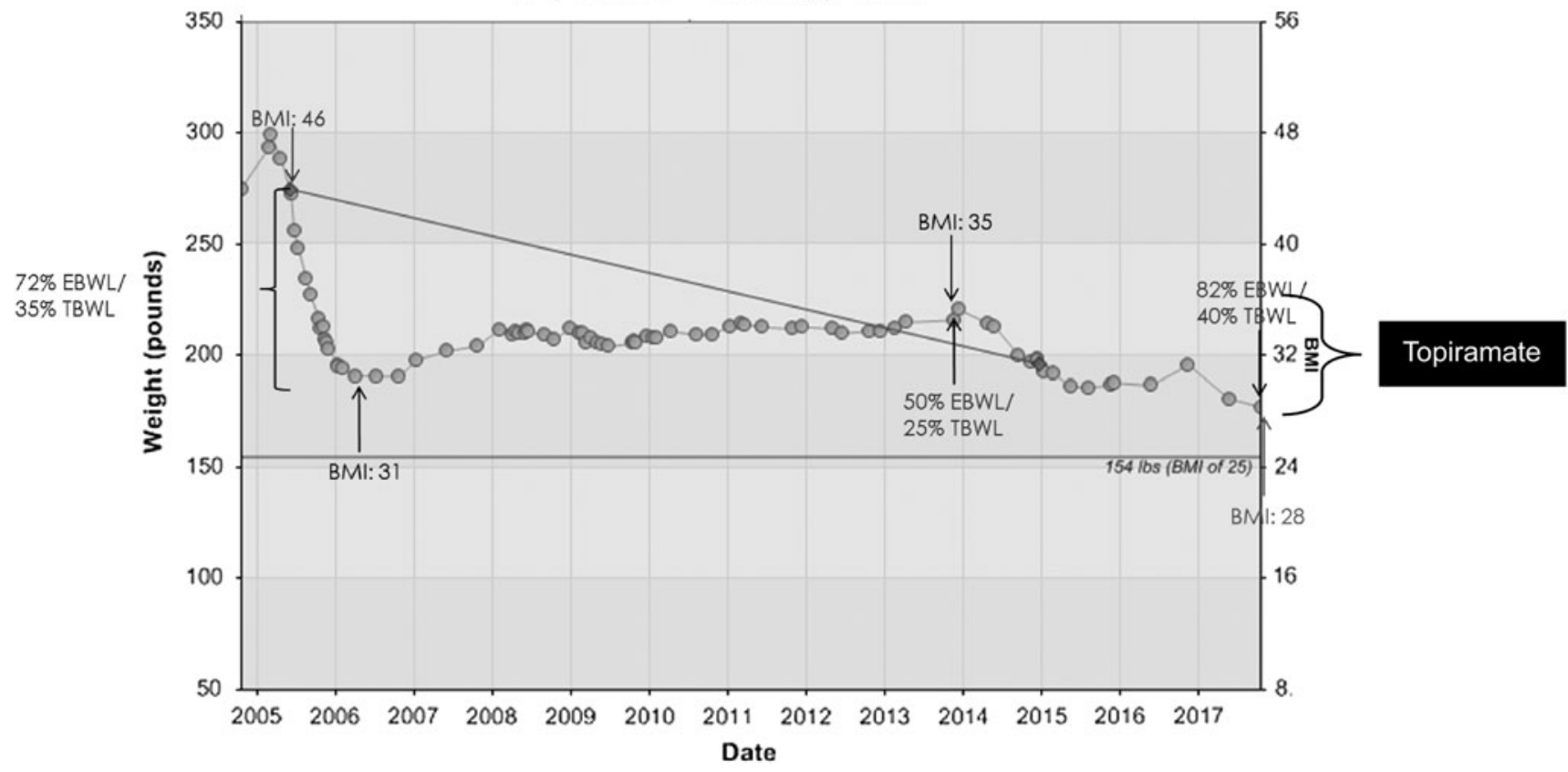

FIG. 1. Graphical representation of weight loss medication after bariatric surgery in a 72-year-old RYGB patient. Note: The patient's weight loss from RYGB was from a BMI of 46-31 (class 1: mild obesity). She regained weight to a BMI of 35 (class 2: moderate obesity). She lost weight after starting on topiramate to a current BMI of 28. BMI, body mass index; EBWL, excess body weight loss; RYGB, Roux-en-Y gastric bypass; TBWL, total body weight loss.

loss after bariatric surgery. ${ }^{26}$ Prospective research studies regarding comorbidities and response to weight loss medication following bariatric surgery are needed to further explore this issue.

There are many limitations to our study due to its retrospective nature. Limitations include missing patient data, no control group, an inability to account for the length of time that patients were on weight loss medications, and confounding factors, including concurrent treatment with weight promoting medications, as well as weight loss medications being evaluated for weight loss potential when they may have been prescribed for other indications. We were also unable to measure the effect of diet and exercise and some medications were prescribed more than others. Despite these limitations, our study data came from two large academic study sites performing the two most common weight loss procedures in the United States, and included a long duration of follow-up, which gave us the ability to assess the long-term efficacy of weight loss medication after bariatric surgery. In addition, patients in our study received multiple weight loss medications, which helped us explore the efficacy of weight loss medications as well as the individual variability of responses to different medications.

\section{Conclusions}

Weight loss medications are a useful tool to confer additional weight loss in adults 60 years of age and older following inadequate weight loss or weight regain after RYGB and SG. RYGB patients in this age group appear to respond better to weight loss medications, but medication is still effective for conferring additional weight loss in SG patients.
Liraglutide may be particularly useful for additional weight loss in adults 60 years of age and older following bariatric surgery, and further studies are needed to confirm this. The presence of hypertension before bariatric surgery may lower the likelihood of achieving weight loss on medications and further studies are needed to explore this finding.

\section{Acknowledgments}

Funding: National Institute of Diabetes and Digestive and Kidney Diseases (R01 DK103946-01A1) and the National Institutes of Health (P30 DK040561). This work was, in part, supported by NIH NIDDK R01 DK103946-01A1 and P30 DK040561.

\section{Author Disclosure Statement}

No competing financial interests exist.

\section{References}

1. Kyrou I, Randeva HS, Tsigos C, Kaltsas G, Weickery MO. Clinical problems caused by obesity. In: De Groot LJ, Chrousos G, Dungan K, Feingold KR, Grossman A, Hershman JM, Koch C, Korbonits M, McLachlan R, New M, Purnell J, Rebar R, Singer F, Vinik A (eds). Endotext [Internet]. South Dartmouth, MA: MDText.com, 2000-2018.

2. Guh DP, Zhang W, Bansback N, Amarsi Z, Birmingham CL, Anis AH. The incidence of co-morbidities related to obesity and overweight: a systematic review and meta-analysis. BMC Public Health 2009;9:88.

3. Ogden CL, Carroll MD, Kit BK, Flegal KM. Prevalence of obesity among adults: United States, 2011-2012. NCHS Data Brief 2013;(131):1-8. 
4. Pajecki D, Santo MA, Kanagi AL, Riccioppo D, de Cleva R, Cecconello I. Functional assessment of older obese patients candidates for bariatric surgery. Arq Gastroenterol 2014;51:25-28.

5. Marihart CL, Brunt AR, Geraci AA. The high price of obesity in nursing homes. Care Manag J 2015;16:14-19.

6. Abbas M, Cumella L, Zhang Y, Choi J, Vemulapalli P, Melvin WS, et al. Outcomes of laparoscopic sleeve gastrectomy and Roux-en-Y gastric bypass in patients older than 60. Obes Surg 2015;25:2251-2256.

7. Buchwald H, Avidor Y, Braunwald E, Jensen MD, Pories W, Fahrbach K, et al. Bariatric surgery: a systematic review and meta-analysis. JAMA 2004;292:1724-1737.

8. Sjostrom L, Peltonen M, Jacobson P, Ahlin S, AnderssonAssarsson J, Anveden A, et al. Association of bariatric surgery with long-term remission of type 2 diabetes and with microvascular and macrovascular complications. JAMA 2014;311:2297-2304.

9. Chang SH, Stoll CR, Song J, Varela JE, Eagon CJ, Colditz GA. The effectiveness and risks of bariatric surgery: an updated systematic review and meta-analysis, 2003-2012. JAMA Surg 2014;149:275-287.

10. Pajecki D, Santo MA, Joaquim HD, Morita F, Riccioppo D, de Cleva R, et al. Bariatric surgery in the elderly: results of a mean follow-up of five years. Arq Bras Cir Dig 2015; 28(Suppl 1):15-18.

11. Musella M, Milone M, Maietta P, Bianco P, Coretti G, Pisapia A, et al. Bariatric surgery in elderly patients. A comparison between gastric banding and sleeve gastrectomy with five years of follow up. Int J Surg 2014;12(Suppl 2):S69-S72.

12. McGlone ER, Bond A, Reddy M, Khan OA, Wan AC. Super-obesity in the elderly: is bariatric surgery justified? Obes Surg 2015;25:1750-1755.

13. Giordano S, Victorzon M. Bariatric surgery in elderly patients: a systematic review. Clin Interv Aging 2015;10:16271635.

14. Gebhart A, Young MT, Nguyen NT. Bariatric surgery in the elderly: 2009-2013. Surg Obes Relat Dis 2015;11:393398.

15. Wolfe BM, Kvach E, Eckel RH. Treatment of obesity: weight loss and bariatric surgery. Circ Res 2016;118:1844 1855.

16. Grams J, Garvey WT. Weight loss and the prevention and treatment of type 2 diabetes using lifestyle therapy, pharmacotherapy, and bariatric surgery: mechanisms of action. Curr Obes Rep 2015;4:287-302.

17. Ochner CN, Teixeira J, Geary N, Asarian L. Greater shortterm weight loss in women 20-45 versus 55-65 years of age following bariatric surgery. Obes Surg 2013;23:1650_ 1654.

18. Contreras JE, Santander C, Court I, Bravo J. Correlation between age and weight loss after bariatric surgery. Obes Surg 2013;23:1286-1289.

19. Stanford FC, Alfaris N, Gomez G, Ricks ET, Shukla AP, Corey KE, et al. The utility of weight loss medications after bariatric surgery for weight regain or inadequate weight loss: a multi-center study. Surg Obes Relat Dis 2017;13: 491-500.

20. Schwartz J, Suzo A, Wehr AM, Foreman KS, Mikami DJ, Needleman BJ, et al. Pharmacotherapy in conjunction with a diet and exercise program for the treatment of weight recidivism or weight loss plateau post-bariatric surgery: a retrospective review. Obes Surg 2016;26:452-458.

21. Jester L, Wittgrove AC, Clark W. Adjunctive use of appetite suppressant medications for improved weight management in bariatric surgical patients. Obes Surg 1996;6: 412-415.

22. Pajecki D, Halpern A, Cercato C, Mancini M, de Cleva R, Santo MA. Short-term use of liraglutide in the management of patients with weight regain after bariatric surgery. Rev Col Bras Cir 2013;40:191-195.

23. Zilberstein B, Pajecki D, Garcia de Brito AC, Gallafrio ST, Eshkenazy R, Andrade CG. Topiramate after adjustable gastric banding in patients with binge eating and difficulty losing weight. Obes Surg 2004;14:802-805.

24. Ferrannini E, Rosenbaum M, Leibel RL. The threshold shift paradigm of obesity: evidence from surgically induced weight loss. Am J Clin Nutr 2014;100:996-1002.

25. Jacobsen LV, Flint A, Olsen AK, Ingwersen SH. Liraglutide in type 2 diabetes mellitus: clinical pharmacokinetics and pharmacodynamics. Clin Pharmacokinet 2016;55:657672.

26. Shantavasinkul PC, Omotosho P, Corsino L, Portenier D, Torquati A. Predictors of weight regain in patients who underwent Roux-en-Y gastric bypass surgery. Surg Obes Relat Dis 2016;12:1640-1645.

Address correspondence to: Fatima Cody Stanford, MD, MPH, MPA

Department of Medicine Massachusetts General Hospital 50 Staniford Street, Suite 430 Boston, MA 02114

E-mail: fstanford@mgh.harvard.edu 